\title{
Uma Abordagem Prática para Implementação da Garantia da Qualidade de Processo e de Produto
}

\author{
João Pablo S. da Silva, Pablo Dall'Oglio, Sergio Crespo, João Carlos Gluz
}

Programa Interdisciplinar de Pós-graduação em Computação Aplicada - Universidade do Vale do Rio dos Sinos (UNISINOS) - São Leopoldo - RS - Brasil

\{jpabloss,pablo.dalloglio\}@gmail.com, \{crespo,jcgluz\}@unisinos.br

\begin{abstract}
The quality of a software product is directly related with the quality of development process that built it. Because of this, it is necessary to implement quality assurance practices in software development organizations. These practices, defined by quality reference models, not establish a clear way to implement itself. To cover this gap, this paper proposes a practical approach to implement the product and process quality assurance, which is experienced in a real software development company.
\end{abstract}

Resumo. Assumindo a premissa de que a qualidade de um produto de software está diretamente relacionada com a qualidade do processo de construção deste software, faz-se necessário lançar mão de práticas de garantia da qualidade. Tais práticas, comumente definidas por modelos de referência de qualidade, não estabelecem claramente como implementá-las, definindo apenas o que deve ser atendido e não como deve ser atendido. Para sanar esta lacuna, este artigo propõe uma abordagem prática para implementação de garantia da qualidade, a qual é experimentada em um ambiente real de desenvolvimento de software.

\section{Introdução}

O mercado está cada vez mais exigente no que se refere à prestação de serviços de desenvolvimento de softwares. Tal característica faz com que os fornecedores tenham comprovada a sua capacidade e maturidade para prestar o serviço contratado. A comprovação desta capacidade e maturidade se dá através do cumprimento dos acordos estabelecidos com o cliente, o que aumenta o grau de confiança do mercado em relação ao fornecedor. Como acelerador deste grau de confiança, surgem os modelos de referência de qualidade, os quais estabelecem objetivos e práticas para todas as disciplinas relacionadas ao desenvolvimento de software [Chrissis, Konrad e Shrum 2007].

Neste contexto, uma das disciplinas básicas tratadas pelos modelos de referência é a de garantia da qualidade, a qual provê às organizações uma clara visão sobre a aderência de seus projetos de desenvolvimento aos processos de software definidos. Implementar garantia da qualidade segundo modelos de referência não é algo trivial para as organizações por dois motivos: primeiro, os modelos de referência estabelecem o que deve ser implementado, mas não descreve como implementar, o que dificulta as atividades de definição da disciplina; segundo, em muitos casos a disciplina não é algo 
conhecido pelas equipes de desenvolvimento, o que dificulta a sua institucionalização [Chrissis, Konrad e Shrum 2007].

Para fechar a lacuna existente entre o que é pedido pelos modelos de referência e como isto pode ser atendido, o presente trabalho apresenta uma abordagem de implementação para garantia da qualidade construída a partir das necessidades reais de uma empresa de desenvolvimento de software. A Seção 2 traz a contextualização e motivação deste trabalho. A Seção 3 apresenta trabalhos relacionados. A Seção 4 faz a fundamentação de conceitos relacionados. A Seção 5 apresenta a solução estabelecida. A Seção 6 mostra os resultados gerados. A Seção 7 traz as conclusões e trabalhos futuros.

\section{Contexto e Motivação}

O presente trabalho surge dentro de um contexto organizacional, onde uma empresa de tecnologia da informação tem a necessidade de obter junto ao Software Engineering Institute (SEI) o laudo de nível 2 de maturidade do Capability Maturity Model Integration $\left(\mathrm{CMMI}^{1}\right)$. A empresa em questão fornece serviços de desenvolvimento de software, está no mercado nacional e internacional a mais de 18 anos e conta com uma estrutura de aproximadamente 1000 colaboradores. Para o pleno atendimento da necessidade da empresa, faz-se necessário atender a um conjunto específico de áreas de processo, Process Area (PA), do CMMI, incluindo a PA que estabelece os objetivos e práticas relacionadas à garantia da qualidade.

No ano de 2007 a empresa deu início aos trabalhos de definição e institucionalização de um processo de desenvolvimento capaz de atender aos objetivos e práticas do CMMI. Por questões de competitividade mercadológica, foram impostas ao trabalho de definição do processo duas restrições, sendo estas: maximização da qualidade agregada ao produto de software e minimização do custo agregado aos controles e monitoramentos definidos pelo modelo de referência de qualidade. Dentre as disciplinas relacionadas, a garantia da qualidade foi particularmente desafiadora pois não fazia parte da cultura das equipes de desenvolvimento. Tal desafio foi o fato gerador e motivador deste trabalho, pois foi necessário estabelecer uma solução ótima, em termos de custo/benefício, para garantia da qualidade.

\section{Trabalhos Relacionados}

Buscas realizadas em repositórios de publicações científicas indicam a existência de diversos trabalhos relacionados à garantia da qualidade de software. As publicações exploram diferentes fatores da garantia da qualidade, tais como: ferramentas de suporte a melhoria contínua de processos [Lee et al. 2005], ferramentas para medição da qualidade de software [Alghamdi, Rufai e Khan 2005], e ferramentas de suporte aos modelos de qualidade em pequenas organizações [Trudel et al. 2006]. Porém, duas publicações, apresentadas a seguir, merecem destaque por se relacionar diretamente com a proposta deste trabalho.

A garantia da qualidade é uma disciplina que extrapola a fronteira da ciência da computação. [Langheinricha e Kaltschmitt 2006] apresentam em seu artigo uma

\footnotetext{
${ }^{1}$ Vide [Chrissis, Konrad e Shrum 2007].
} 
metodologia para implementação da garantia da qualidade na indústria de biocombustíveis. Os autores defendem a ideia de que o monitoramento e controle efetivo do processo de produção é chave para a qualidade do produto gerado. Mesmo sendo definida para outra área que não a computação, a metodologia traz a tona algumas necessidades também relevantes para a garantia da qualidade aplicada ao software, tais como: ter um processo definido, identificar fatores que influenciam a qualidade, identificar pontos de controle, estabelecer medidas apropriadas e monitorar não conformidades até seu fechamento.

No âmbito da ciência da computação, [Elberzhager e Denger 2007] estabelecem em seu artigo um framework para seleção e customização de técnicas de garantia da qualidade. Os autores argumentam que a qualidade final de um produto de software é um fator decisivo para uma organização e que esta qualidade é atingida através verificação dos produtos de trabalhos intermediários, gerados ao longo do ciclo de vida. Uma questão pertinente abordada pelos autores é a necessidade de se utilizar técnicas distintas para cada momento do ciclo de vida do software. Essencialmente, o framework proposto estabelece um conjunto de técnicas aplicáveis ao projeto, as quais são selecionadas em função dos fatores que influenciam a qualidade do produto de software.

\section{Fundamentação Teórica}

Para o pleno entendimento deste trabalho, faz-se necessário entender dois conceitos fundamentais, sendo estes: processo de software, o qual estabelece como o produto de software deve ser construído; e o de garantia da qualidade, a qual estabelece como a execução do processo de software deve ser monitorada. Complementarmente, pode-se observar a relação de dependência unidirecional entre os conceitos, pois a garantia da qualidade só existe em função do processo de software, enquanto que, processos de software não dependem da garantia da qualidade para existir.

\subsection{Processo de Software}

Abordagens de engenharia de software, essencialmente, se apoiam em compromissos com a qualidade, tendo como principal alicerce uma camada de processos de software, os quais estabelecem frameworks capazes de efetivamente entregar o produto requerido [Pressman 2001]. Refinando esta definição, pode-se dizer que um processo de software é um conjunto de atividades e resultados associados, os quais levam a um produto de software [Sommerville 2001]. Um framework genérico de processo, é composto por frameworks de atividades aplicáveis a qualquer projeto de desenvolvimento de software. Cada framework de atividades é composto por uma coleção de tarefas e produtos de trabalho [Pressman 2001].

O CMMI classifica os processos de software segundo sua maturidade, a qual remete a melhoria contínua dos processos da organização através de um conjunto de áreas de processo, Process Area (PA), organizados segundo critérios definidos pelo modelo. A Figura 1 apresenta a hierarquia de níveis de maturidade, Maturity Level (ML) estabelecido pelo CMMI. O nível Inicial se caracteriza por processos ad hoc que tendem ao caos, o sucesso em projetos de desenvolvimento, quando obtido, é reflexo de esforços individuais. O nível Gerenciado garante que o projeto de desenvolvimento é planejado e executado, os recursos têm as habilidades necessárias e a aderência ao processo é garantida [Chrissis, Konrad e Shrum 2007]. 
O nível Definido é caracterizado por padrões, procedimentos, ferramentas e métodos, onde cada projeto estabelece seu processo a partir do processo padrão da organização. O nível Quantitativamente Gerenciado se caracteriza pelo pleno uso de medidas no planejamento e monitoramento, onde objetivos quantitativos são definidos com base em critérios orientados a qualidade e produtividade do processo. Por fim, o nível Otimizado é caracterizado pela melhoria contínua baseada no pleno entendimento quantitativo do processo, ou seja, processos estratégicos são identificados, medidos e melhorados [Chrissis, Konrad e Shrum 2007].

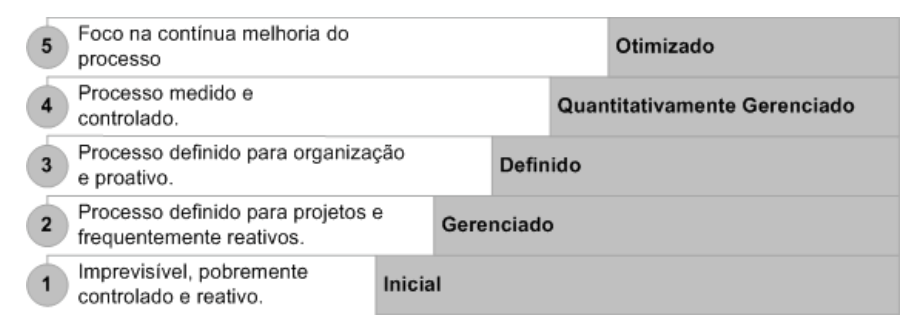

Figura 1. Os cinco níveis de maturidade de um processo.

\subsection{Garantia da Qualidade}

Assumindo a premissa que a qualidade de um produto de software é altamente influenciada pela qualidade do processo que construiu este software, faz-se necessário lançar mão de mecanismos de monitoramento capazes de dar uma clara visão sobre a execução dos processos de software. O Software Engineering Body of Knowledge (SWEBOK) diz que o papel da garantia da qualidade é se certificar que um processo é executado como planejado, provendo para a organização um conjunto de indicadores de processo. Em outras palavras, a garantia da qualidade é responsável por monitorar a execução do processo, e os resultados gerados a partir deste monitoramento devem ser externados para as gerências responsáveis pela execução de projetos de software [Abran et al. 2004].

Para fins de desambiguação, cabe diferenciar o conceito de garantia da qualidade do conceito de controle da qualidade. A garantia da qualidade é formada por um conjunto sistemático e planejado de atividades que, quando seguidas, garantem aos clientes que os produtos ou serviços atendem às suas expectativas. Em outras palavras, pode se dizer que garantia da qualidade remete ao como fazer o software, que por sua vez remete ao conceito de processo de software. Por outro lado, o controle da qualidade é a comparação de um determinado produto ou serviço com suas respectivas especificações, onde todo e qualquer desvio identificado é devidamente registrado e endereçado. O controle da qualidade é uma atividade inserida em processo de software que garante o pleno funcionamento do produto ou serviço de acordo com os requisitos previamente levantados [Bastos et al. 2007].

O CMMI trata a garantia da qualidade como uma PA, exigida para se atingir o nível 2 de maturidade. A garantia da qualidade de processo e de produto, Product and Process Quality Assurance (PPQA), é uma PA de suporte do CMMI, que provê às gerências da organização uma visão objetiva sobre a execução dos processos e produtos de trabalho relacionados. Cabe observar que não se deve confundir produto de software com produto de trabalho. Produto de software é a meta do projeto, é o programa ou sistema a ser desenvolvido pela equipe, enquanto que, produto de trabalho são todos os 
artefatos meio do projeto, ou seja, documentos de gerenciamento e engenharia, tais como: Plano de Projetos, Modelo de Casos de Uso, etc. Fundamentalmente, PPQA envolve a avaliação objetiva da execução dos processos e produtos de trabalho contra descrições de processo, procedimentos e padrões [Chrissis, Konrad e Shrum 2007].

PPQA busca também, a identificação e o acompanhamento de não conformidades, garantindo seu devido fechamento. Não conformidades são desvios na execução do processo que podem expor o projeto de desenvolvimento a riscos relacionados ao escopo, custo, tempo ou qualidade. Garantir o fechamento significa monitorar e apoiar a equipe de desenvolvimento na resolução do problema e não realizar a correção propriamente dita. Por fim, PPQA explicita informações sobre a aderência dos projetos de desenvolvimento aos processos definidos, provendo a fundamentação necessária para a tomada de decisão por parte das gerências competentes, avaliação e melhoria contínua dos processos de desenvolvimento [Chrissis, Konrad e Shrum 2007].

Como todas as demais PAs do CMMI, PPQA é organizada em objetivos específicos, Specific Goal (SG), que por sua vez são organizados em práticas específicas, Specific Practice (SP), como visualizado na Figura 2. O primeiro objetivo definido, SG 1, diz respeito à avaliação objetiva da aderência dos processos e produtos de trabalho elaborados contra descrições de processo, procedimentos e padrões. Este objetivo é composto pelas práticas para avaliação objetiva de processos, SP 1.1, e de produtos de trabalho e serviços, SP 1.2. O segundo objetivo, SG 2, propõe uma percepção clara e objetiva do projeto em termos de desvios e suas correções. O objetivo é composto pela prática de comunicação e monitoramento das não conformidades até que estas sejam fechadas, SP 2.1, e pela prática de geração de registros para uso como base de conhecimento em ações de melhoria contínua, SP 2.2, [Chrissis, Konrad e Shrum 2007].

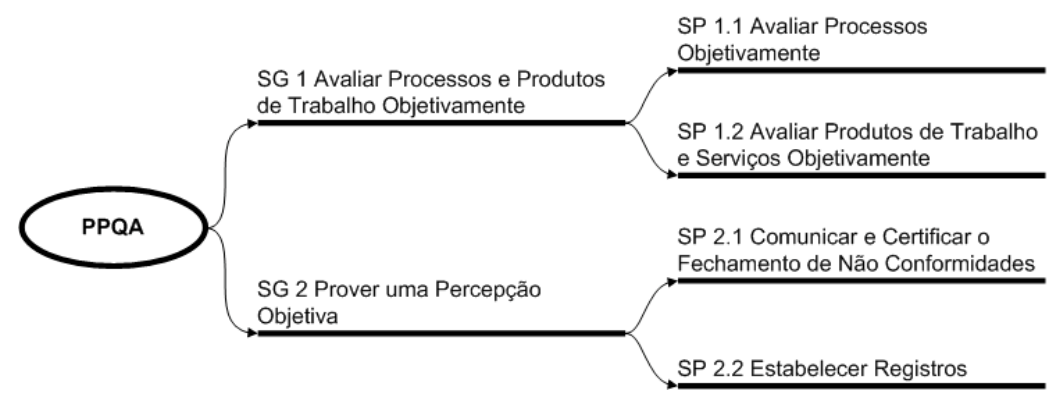

Figura 2. Estrutura hierárquica de PPQA.

\section{Uma Abordagem para Implementação de PPQA}

Como um produto derivado do processo definido e institucionalizado na empresa anteriormente citada, tem-se uma abordagem de implementação de PPQA fundamentada em três princípios. O primeiro diz respeito ao pleno atendimento dos objetivos da PA, garantindo o sucesso em avaliações oficiais para obtenção de laudos de maturidade CMMI. O segundo se refere à relação custo/benefício, buscando minimizar o esforço necessário para execução das atividades sem perder a cobertura necessária para garantir o monitoramento do processo. O terceiro diz respeito à percepção da equipe de desenvolvimento sobre a importância da PA, a qual deve sustentar a garantia da qualidade como uma ferramenta de suporte ao desenvolvimento. 
Podem ser observadas na Figura 3, as três frentes distintas para implementar PPQA. A primeira remete ao mapeamento de pontos críticos de um processo através do levantamento dos principais produtos de trabalho e a geração de uma coleção de itens de revisão que garantam a verificação dos fatores de sucesso para o projeto. A segunda remete à execução das inspeções em projetos através da definição de escopo, seleção e análise de amostras, e corroboração e publicação dos resultados. A terceira estabelece dois indicadores fundamentais para o monitoramento, tanto dos projetos de desenvolvimento, quanto das próprias atividades de garantia da qualidade.

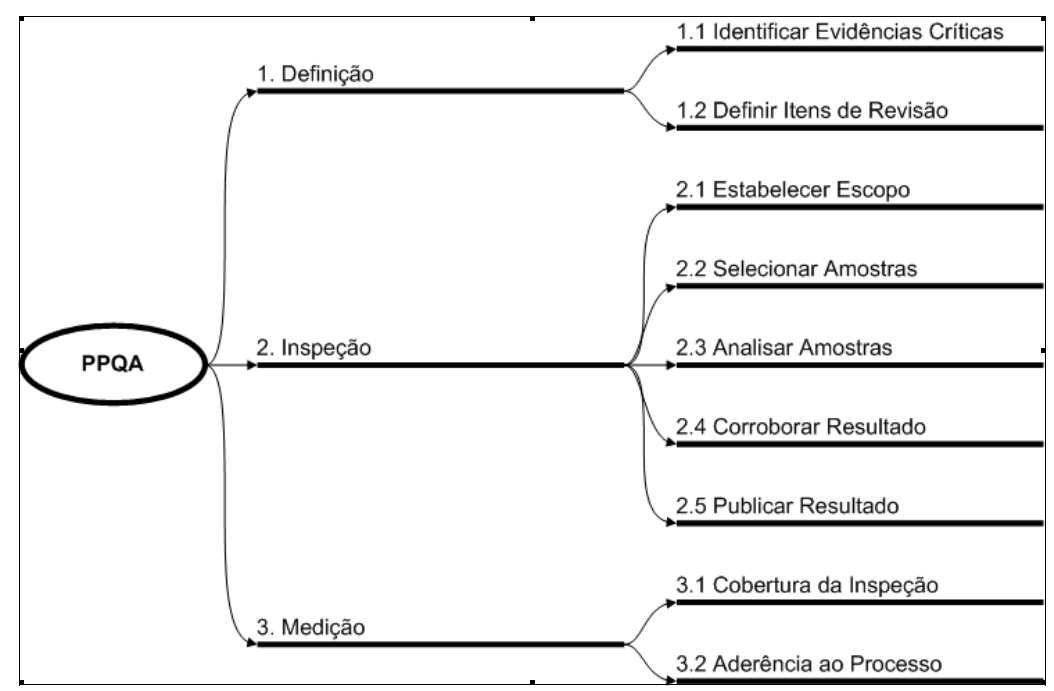

Figura 3. Visão geral da solução definida para implementação de PPQA.

\subsection{Definição}

A primeira frente apresentada diz respeito às definições básicas realizadas antes de se dar início as inspeções de projeto propriamente ditas. Inicialmente, cabe observar que as atividades de definição não são atividades recorrentes como as atividades de inspeção de projetos. Uma vez estabelecidas as definições necessárias, estas tendem a se estabilizar. Entretanto, como previsto pelo CMMI, tais definições devem ser revisadas sempre que o ocorrer algum tipo de modificação significativa nos processos, padrões ou procedimentos da organização.

\subsubsection{Identificar Evidências Críticas}

A identificação de evidências críticas é uma atividade fundamental para as definições básicas da implementação de PPQA, pois uma forma de se conseguir uma boa relação custo/benefício é identificar os artefatos que estão no caminho crítico da qualidade do projeto, ou seja, documentos que se construídos de forma incorreta impactam diretamente na qualidade do produto solicitado pelo cliente. Por exemplo, se uma Lista de Requisitos não for devidamente estruturada e escrita, a equipe de desenvolvimento pode não entender o escopo e construir algo não solicitado, o que impacta no orçamento do projeto. Para identificar as evidências críticas, faz-se necessário um estudo, tanto do processo de desenvolvimento, quanto do histórico de projetos da organização. Assim torna-se possível mapear quais e quando os produtos de trabalho devem ser devidamente inspecionados. 


\subsubsection{Definir Itens de Revisão}

Uma vez mapeados os produtos de trabalho pertencentes ao caminho crítico da qualidade, faz-se necessário enumerar para cada um, todas as características que garantem sua qualidade. Se nas inspeções for possível identificar tais características nos artefatos gerados, pode-se concluir que estes estão aderentes ao processo definido. Cada característica enumerada vira um item de revisão, o qual sempre deve ter uma avaliação binária: Atende ou Não Atende. Por exemplo, pode-se enumerar as seguintes características, consequentemente itens de revisão, de um plano de gerenciamento de riscos:

- os riscos identificados estão descritos de forma clara e objetiva;

- cada risco está devidamente qualificado;

- está definido para cada risco uma ação de resposta devidamente planejada;

- para cada risco está definida pelo menos uma ação de contingência.

\subsection{Inspeção}

A segunda frente estabelecida caracteriza as inspeções dos projetos de software. Dados os objetivos de uma implementação de PPQA, esta se torna a frente mais importante, pois é nela que todas as práticas da PA são plenamente atendidas. Neste contexto, podese dizer que Definição e Medição são frentes de apoio à Inspeção. As atividades definidas dentro de Inspeção a tornam capaz de dar aos interessados uma plena e transparente visão da execução dos projetos de desenvolvimento no que se refere à aderência aos processos definidos pela organização. Cabe ainda salientar, que a inspeção é altamente recorrente, ou seja, são aplicadas em um projeto quantas vezes for necessário para garantir a execução do processo.

\subsubsection{Estabelecer Escopo}

É natural pensar que os projetos executam seus processos de forma contínua, logo, as inspeções devem cobrir o exato ponto de execução do processo. Para tal, faz-se necessário avaliar o status do projeto e decidir quais itens de revisão são aplicáveis neste momento. Esta é uma atividade repetida a cada inspeção e de rápida execução, pois o maior esforço deve ser concentrado na inspeção propriamente dita. Para exemplificar, suponha-se que um projeto, ao executar o Unfied Process ${ }^{2}$ (UP), esteja na fase de Construção, logo, não faz sentido aplicar itens de revisão que cobrem a fase de Concepção, pois isto é algo já superado pelo projeto e eventuais correções em artefatos desta fase não agregam mais valor.

\subsubsection{Selecionar Amostras}

Uma vez estabelecido o escopo da inspeção, faz-se necessário colher amostra dos produtos de trabalho para efetivamente executar a inspeção. Nesta atividade, cabe a aplicação de técnicas de amostragem para garantir um resultado plausível com a realidade do projeto. Por exemplo, ao buscar amostras de Atas de Reunião, poderia ser adotada uma amostragem estratificada por datas, sendo selecionado o artefato mais

\footnotetext{
${ }^{2}$ Vide [Larman 2004].
} 
antigo, o mediano e o mais novo. Já para a seleção de amostras de Diagramas de Caso de Uso, a amostragem pode ser estratificada por pacote e redator, colhendo um artefato de cada pacote para cada analista envolvido no projeto.

\subsubsection{Analisar Amostras}

A análise das amostras colhidas caracteriza a inspeção propriamente dita. É neste momento que se busca no artefato as características de qualidade, itens de revisão, enumeradas na Definição. Ao ponderar sobre cada item de revisão se deve chegar a uma conclusão sobre seu atendimento. É importante observar que a decisão de Atende ou Não Atende, é sempre tomada sobre o conjunto de amostras, ou seja, caso uma das amostras não atenda ao item de revisão em questão, todas as demais são desqualificadas e o item é considerado Não Atende. Por outro lado, se todas as amostras atenderem ao item de revisão este é considerado Atende. Tal critério garante a avaliação objetiva exigida pelo CMMI.

\subsubsection{Corroborar Resultado}

A equipe de desenvolvimento não deve ter a sensação de que o resultado de uma inspeção é algo externo ao projeto e imposto à equipe. Tal situação leva a PA ao descrédito, consequentemente, vira custo sem agregar valor. Uma forma simples de contornar este problema é corroborar o resultado junto aos representantes da equipe, tais como: Gerente de Projeto, Líder Técnico, etc. Ao apresentar o resultado, deve-se obter o consenso de todos, sempre usando uma abordagem argumentativa. Isto reforça a necessidade de ter como Analista de Qualidade um profissional com conhecimento e experiência em gerenciamento e engenharia.

\subsubsection{Publicar Resultado}

Como exigido pelo CMMI, o resultado das inspeções deve ser de conhecimento de todos os envolvidos, logo, faz-se necessário publicá-lo para a equipe do projeto e para as gerências diretamente superiores ao projeto. Assim, todos tem ciência sobre os riscos levantados, sobre as não conformidades endereçadas e sobre as suas responsabilidades para com o processo.

\subsection{Medição}

Como já observado, a frente de Medição dá suporte à frente de Inspeção, pois nela são definidos dois indicadores básicos para avaliação dos projetos e suas inspeções. $\mathrm{O}$ CMMI recomenda o uso de medidas para monitorar processos e projetos. No que se refere à PPQA, a lógica é a mesma, ou seja, faz-se necessário ter um conjunto mínimo de indicadores capazes de prover uma objetiva e clara percepção sobre a cobertura obtida durante as inspeções e sobre a aderência do projeto ao processo definido.

\subsubsection{Cobertura da Inspeção}

A cobertura da inspeção indica o quão boa foi a Definição, que estabelece o conjunto de itens de revisão, e o quão criterioso foi o Analista de Qualidade ao definir o escopo, pois este é o responsável por identificar itens aplicáveis e não aplicáveis. O cálculo deste indicador se dá através da razão entre o Total de Itens de Revisão Aplicáveis (TIRA) e o Total de Artefatos Inspecionáveis (TAI). Para entender o número gerado, é preciso 
saber que quanto maior for o grau obtido melhor está a cobertura da inspeção em questão. Um projeto que tenha obtido grau 4 tem melhor cobertura que um que tenha obtido grau 2, porque o primeiro tem em média 4 itens de revisão para cada artefato, enquanto que, o segundo tem em média 2 itens de revisão para cada artefato. A Tabela 1 exemplifica este cenário.

Tabela 1. Exemplo de cálculo de cobertura de inspeção.

\begin{tabular}{|r|l|r|r|}
\hline \multicolumn{2}{|c|}{ Projeto 1 } & \multicolumn{2}{|c|}{ Projeto 2 } \\
\hline TIRA & 40 & TIRA & 20 \\
\hline TAI & 10 & TAI & 10 \\
\hline TIRA / TAI & 04 & TIRA / TAI & 02 \\
\hline
\end{tabular}

\subsubsection{Aderência ao Processo}

A aderência ao processo indica o quão próximo está o projeto daquilo que o processo entende como ideal. Este indicador gera um valor percentual, onde $100 \%$ indica total aderência e $0 \%$ indica nenhuma aderência. Para calcular, faz-se necessário obter a razão entre o Total de Itens de Revisão Atendidos (TIRAt) e o Total de Itens de Revisão Aplicáveis (TIRAp). Um projeto que tenha em seu escopo de inspeção 10 itens de revisão e tenha recebido Atende em 5 itens de revisão, tem como grau de aderência o valor de 0,5 , ou seja, $50 \%$ de aderência ao processo. A Tabela 2 apresenta um exemplo para o cálculo deste indicador.

Tabela 2. Exemplo de cálculo de aderência ao processo.

\begin{tabular}{|c|c|c|}
\hline TIRAt & TIRAp & TIRAt / TIRAp \\
\hline 05 & 10 & 0,5 \\
\hline
\end{tabular}

\section{Resultados Obtidos com a Solução}

A solução estabelecida e integrada ao processo de desenvolvimento da empresa, citada na Seção 2 deste trabalho, comprovou sua eficiência sendo aprovada em uma avaliação formal CMMI. Em Dezembro de 2007 a empresa obteve do SEI um laudo de nível 2 de maturidade e, desde então, o processo de desenvolvimento, juntamente com a solução de implementação de PPQA, se mantém em produção e em contínua melhoria. Atualmente, a empresa trabalha a implementação de outras PAs, objetivando a obtenção junto ao SEI de um laudo de maturidade de nível 3.

A Figura 4 apresenta um fragmento do principal produto de trabalho gerado pela solução apresentada neste artigo. Este produto de trabalho é um Modelo de Relatório de Garantia da Qualidade que consolida o conjunto de itens de revisão definidos para garantir a plena cobertura do processo. Além disto, o relatório é a ferramenta de trabalho em inspeções, registrando os pareceres sobre o atendimento de cada item e as não conformidades identificadas. Ao final de cada inspeção o relatório devidamente preenchido é publicado para a equipe do projeto e para as gerências diretamente superiores.

Para evidenciar os resultados obtidos com a abordagem apresentada neste artigo, foi realizado um trabalho de medição, conforme apresentado na Seção 5.3. Para calcular os indicadores de Cobertura de Inspeção e Aderência ao Processo foi selecionada uma amostra de 10 projetos executados entre 2007 e 2009. Para cada projeto, foram 
selecionadas 4 inspeções de garantia da qualidade, sendo uma para cada fase definida no processo de desenvolvimento da empresa. Isto totaliza uma amostra de 40 inspeções.

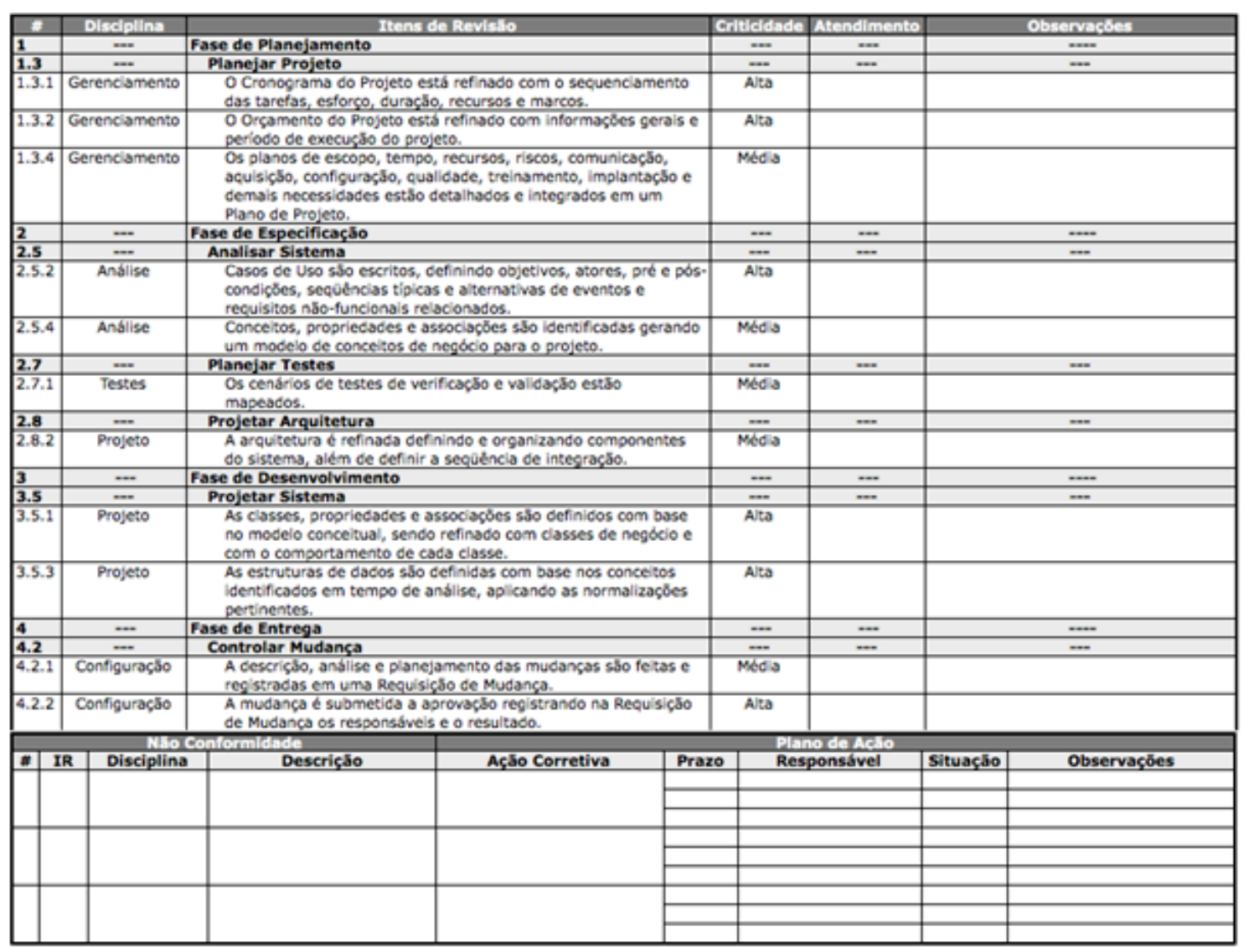

Figura 4. Fragmento de um relatório de garantia da qualidade.

O gráfico da Figura 5 mostra o comportamento do indicador de Cobertura de Inspeções, calculado a partir da amostra anteriormente definida. Pode-se observar que a fase com melhor cobertura é a de Planejamento, com 2,11 itens de revisão para cada produto de trabalho. A fase de Especificação apresenta uma queda considerável, onde a cobertura é de 1,68. A fase de Desenvolvimento melhora o cenário de cobertura, com o valor de 1,92. Já a fase de Entrega novamente derruba o indicador, tendo esta fase a menor cobertura, apenas 1,63.

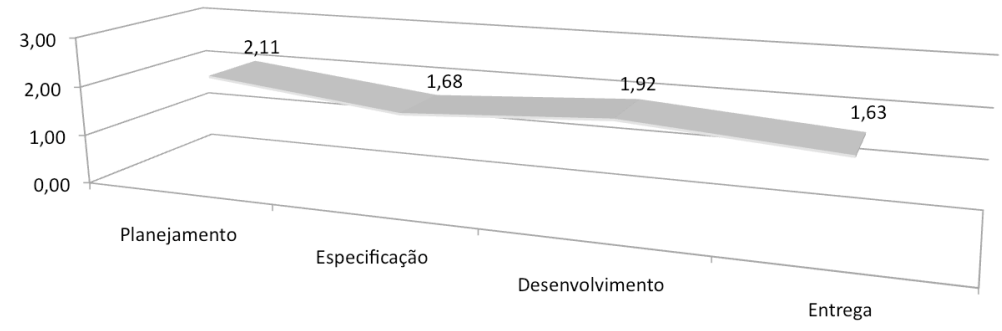

Figura 5. Gráfico para o indicador Cobertura de Inspeção.

Também pode ser observada no gráfico da Figura 5, a homogeneidade dos dados. Tal observação se confirma através do cálculo do coeficiente de variação da amostra, sendo este de 10,37\%. Outro dado relevante de se observar é o valor médio do indicador de Cobertura de Inspeção, o qual demonstra a granularidade das inspeções. 
Considerando o universo da amostra, 40 inspeções, o indicador possui um valor médio de 1,86 itens de revisão por produto de trabalho, o que indica uma granularidade muito grossa. Inspeções com granularidade grossa tendem a não ser objetivas como recomenda o CMMI.

A Figura 6 apresenta um gráfico que consolida os valores de Aderência ao Processo da amostra estabelecida. Inicialmente, pode-se observar um valor de Aderência ao Processo de $80,78 \%$ na fase de Planejamento. Na sequência, há uma elevação deste valor para $86,27 \%$. Porém, as fases de Desenvolvimento e Entrega quebram a tendência de crescimento, gerando para o indicador os valores $83,91 \%$ e $81,32 \%$, respectivamente.

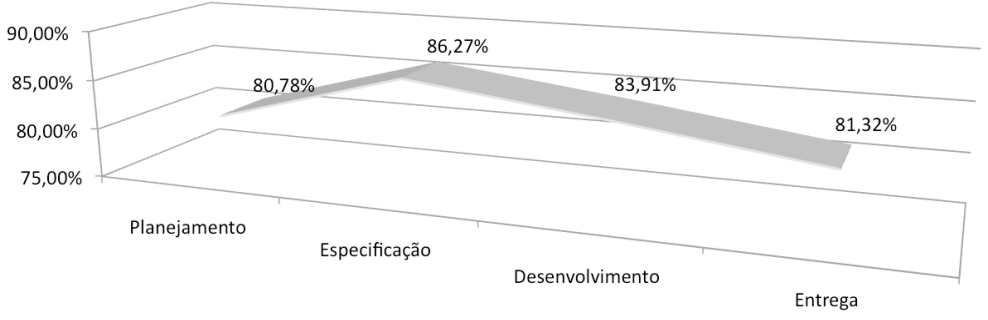

Figura 6. Gráfico para o indicador Cobertura de Inspeção.

Ao observar o comportamento do gráfico, nota-se que o universo desta amostragem é menos homogêneo, se comparado com o indicador anteriormente apresentado. Mas, estatisticamente, o coeficiente de variação ainda é considerado baixo, pois apresenta um valor igual a 13,31\%. O indicador de Aderência ao Processo tem como média final da amostragem um valor de $83,07 \%$, ou seja, em média, aproximadamente $20 \%$ do processo definido pela empresa não é seguido pelas equipes em projetos de desenvolvimento.

\section{Conclusões}

Ao longo do presente artigo, fica evidenciada a importância dada aos processos de desenvolvimento de software, pois se acredita que a qualidade de um produto de software está diretamente relacionada à qualidade do processo que originou o produto de software. Seguindo esta linha, o CMMI define uma PA de garantia da qualidade de processo e de produto, PPQA, porém não estabelece como suas práticas podem ser de fato implementadas. Este artigo vem para oferecer uma alternativa para esta necessidade, através da definição de uma abordagem prática para a implementação de PPQA.

Ao confrontar a solução apresentada com as práticas da PA, fica evidenciado o pleno atendimento dos objetivos definidos pelo modelo CMMI. Esta conclusão é corroborada com o sucesso obtido na avaliação formal CMMI e pelo fato da empresa manter a solução em produção atualmente. Além disso, a análise do parecer dado pela empresa indica que o ponto forte da solução é a transparência que esta dá ao processo de inspeção. As gerências tem ciência de quão aderente estão os projetos em relação aos processos definidos. As equipes veem a disciplina como uma ferramenta de apoio ao desenvolvimento, onde é possível obter suporte e solucionar impedimentos.

A análise do indicador de Aderência ao Processo apresenta um valor médio plausível para um projeto de desenvolvimento, onde menos de $20 \%$ das atividades 
executadas apresentaram algum tipo de não conformidade. Por outro lado, o indicador de Cobertura de Inspeção mostra uma baixa cobertura média, menos de 2 itens por produto de trabalho. Isto ocorre em função de uma granularidade grossa dos itens de revisão. A desvantagem de se ter itens de revisão com uma granularidade grossa é que se faz necessário ter Analistas de Qualidade experientes nas atividades de inspeção.

Fica como proposta de trabalho futuro, o estabelecimento de uma ferramenta de apoio para as atividades de inspeção de garantia da qualidade, que possibilite uma execução criteriosa das atividades de Definição apresentadas na Seção 5.1. Como resultado desta execução criteriosa se deve obter uma granularidade mais fina das inspeções. Complementarmente, esta ferramenta de apoio deve garantir a manutenção do esforço despendido em inspeções, ou seja, aumentar a cobertura sem impactar nos custos.

\section{Referências}

Abran, A. and Moore, J. W. and Bourque, P. and Dupuis, R. (2004), Guide to the Software Engineering Body of Knowledge, IEEE Computer Society.

Alghamdi, J. S. and Rufai, R. A. and Khan, S. M. (2005), OOMeter: A Software Quality Assurance Tool, In IEEE European Conference on Software Maintenance and Reengineering.

Bastos, A. and Rios, E. and Cristalli, R. and Moreira, T. (2007), Base de Conhecimento em Teste de Software, Martins Editora.

Chrissis, M. B. and Konrad, M. and Shrum, S. (2007), CMMI Guidelines for Process Integration and Product Improvement, Addison Wesley.

Elberzhager, F. and Denger, C. (2007), A Comprehensive Planning Framework for Selecting and Customizing Quality Assurance Techniques, In IEEE Conference on Software Engineering and Advanced Applications.

Larman, C. (2004), Utilizando UML e Padrões: Uma introdução à análise e ao projeto orientado a objetos e ao Processo Unificado. Bookman.

Langheinricha, C. and Kaltschmitt, M. (2006), Implementation and Application of Quality Assurance Systems, In Biomass and Bioenergy.

Lee, J. W. and Jung, S. H. and Park, S. C. and Lee, Y. J. and Jang, Y. C. (2005), System Based SQA and Implementation of SPI for Successful Projects, In Information Reuse and Integration.

Pressman, R. S. (2001), Software Engineering: A Practitioner's Approach, McGrawHill.

Sommerville, I. (2001), Software Engineering, Addison Wesley.

Trudel, S. and Lavoie, J. and Paré, M and Suryn, W. (2006), PEM: The Small Company-Dedicated Software Process Quality Evaluation Method Combining CMMI and ISO/IEC 14598, In Software Quality Journal. 